\title{
Editorial
}

\section{Melhorias editoriais em 2018 e 2019}

No ano de 2018 publicamos o volume 7 com 12 números, cada número com 15 manuscritos, totalizando doze edições, uma a cada mês. Notamos que a demanda de publicação da revista aumentou em virtude da melhoria na pontuação do Qualis CAPES. Desse modo, para 2019 aumentaremos a quantidade de manuscritos por número e continuaremos trabalhando com a publicação contínua de artigos conforme orientações da SciELO, de modo a agilizar o fluxo de informações.

Em 2018 melhoramos nossa política de ética da publicação e declaração de negligência de publicação. Para tanto a Research, Society and Development endossou o CONSORT (Consolidated Standards of Reporting Trials) para submissão de resultados de estudos randomizados na área de saúde. Também assinamos a San Francisco Declaration on Research Assessment (DORA).

Durante o ano de 2018 também passamos a utilizar o Digital object identifier (DOI) como forma de melhorar a segurança, recuperação e armazenamento dos manuscritos publicados pela revista. O financiamento para a implantação do DOI foi (e poderá continuar sendo) da Universidade Federal de Itajubá.

Para o ano de 2019 são esperadas novas parcerias para dossiês temáticos, bem como o apoio a eventos científicos através de fast-track, como forma de atender melhor à comunidade científica e consequentemente à sociedade, que se beneficia com os mais recentes avanços da ciência que podem ser divulgados pela revista.

Agradecemos a todos que contribuíram com a revista durante o ano de 2018 (autores, revisores, membros do comitê editorial e científico) e esperamos que estejam conosco durante o ano de 2019.

Dr. Ricardo Shitsuka

Editor 